\title{
RESÍDUOS INDUSTRIAIS E A INVISIBILIDADE DE SEUS RISCOS SOCIOAMBIENTAIS
}

\author{
INDUSTRIAL WASTE AND THE INVISIBILITY OF THEIR SOCIAL \\ ENVIRONMENTAL RISKS
}

\section{LOS RESIDUOS INDUSTRIALES Y LA INVISIBILIDAD DE SUS RIESGOS SOCIALES Y AMBIENTALES}

\section{Clesley Maria Tavares Nascimento}

Mestre em Desenvolvimento e Meio Ambiente pela Universidade Federal do Ceará - UFC. Doutoranda em Geografia pela Universidade Estadual do Ceará-UECE. ). Docente na Universidade Regional do Cariri (URCA).

Rua Mons. Silvano de Sousa, 39, Ap.202. Caixa d'água, Crato- CE. CEP 63000-000.

Email:clesleytavares@gmail.com.

\section{Maria Lúcia Brito da Cruz}

Doutorado em Geografia pela Universidade Federal de Pernambuco (UFPE). Docente na Universidade Estadual do Ceará (UECE).

Rua Abílio Martins, 1545, Amadeu Furtado, Fortaleza - CE. CEP 60455470.

Email:mlbcruz@gmail.com

\section{RESUMO}

O presente artigo traz uma discussão sobre os riscos socioambientais e as vulnerabilidades decorrentes da gestão dos resíduos sólidos industriais perigosos no distrito industrial de Maracanaú-CE. De modo geral, as informações referentes a quantificação do volume dos resíduos industriais perigosos gerados no município, se deu através de consulta dos planos de gerenciamento de resíduos sólidos de 20 indústrias, enviados a Superintendência de Meio Ambiente do Ceará - SEMACE. Resultados parciais indicaram que ineficácia de uma fiscalização efetiva e a falta de transparência por parte dos donos das indústrias dificultam uma gestão adequado deste tipo de resíduos, e corrobora com a hipótese de que a gestão dos resíduos sólidos perigosos no distrito industrial de Maracanaú expõe a população a situações conjunturais de risco ambiental e vulnerabilidade social.

PALAVRAS-CHAVES: Gestão de resíduos sólidos, resíduos industriais perigosos, risco socioambiental, vulnerabilidade social.

\section{ABSTRACT}

This article provides a discussion of the social and environmental risks and vulnerabilities stemming from the management of hazardous industrial solid waste in the industrial district of Maracanaú-CE. Generally, the information regarding the quantification of the volume of hazardous industrial waste generated in the city, 
was made through consultation of solid waste management plans for 20 industries, sent the Superintendência de Meio Ambiente do Ceará - SEMACE. Partial results indicated that ineffectiveness of effective supervision and the lack of transparency on the part of owners of industries, hinder the proper management of such waste, and corroborates the hypothesis that the management of hazardous waste in the industrial district of Maracanaú exposes the population short-term environmental risk and social vulnerability.

KEYWORDS: Solid waste management, hazardous industrial waste, environmental risk, social vulnerability.

\section{RESUMEN}

Este artículo ofrece un análisis de los riesgos y vulnerabilidades sociales y ambientales derivados de la gestión de los residuos sólidos industriales peligrosos en el distrito industrial de Maracanaú-CE. En general, la información sobre la cuantificación del volumen de los residuos industriales peligrosos generados en la ciudad, se hizo a través de la consulta de los planes de gestión de residuos sólidos de 20 industrias, envió a la Superitendência de Meio Ambiente de Ceará - SEMACE. Los resultados parciales indican que la ineficacia de la supervisión efectiva y la falta de transparencia por parte de los propietarios de industrias, obstaculizar la correcta gestión de estos residuos, y corrobora la hipótesis de que la gestión de residuos peligrosos en el distrito industrial de revelaciones Maracanaú la población a corto plazo del riesgo ambiental y vulnerabilidad social.

PALABRAS CLAVE: gestión de residuos sólidos, residuos industriales peligrosos, riesgo ambiental, vulnerabilidad social. 


\section{INTRODUÇÃO}

A imanência existente na relação dos resíduos sólidos e os espaços sociais nos quais estão circunscritos é resultante do modo de vida capitalista, fundado no processo de produção industrial que produz alterações substanciais na natureza, tanto no tempo quanto no espaço. Destarte, os resíduos sólidos tornam-se elementos atuantes na dinâmica de construção do espaço geográfico, deixando um rastro de sérios problemas socioambientais que afetam comunidades inteiras e as expõem em situações de vulnerabilidade e risco.

A tipologia dos riscos é vasta (risco natural, risco alimentar, risco econômico, risco geopolítico, risco social e outros), no entanto este artigo irá deter-se aos riscos ocasionados pelos resíduos industriais classe I, considerados perigosos devido suas propriedades ${ }^{1}$ físicas, químicas ou infecto-químicas poderem vir ocasionar riscos à saúde pública e/ou ao meio ambiente quando gerenciados de forma inadequada.

As indústrias são diretamente afetadas pela gestão do risco, pois a legislação e as normas técnicas as obrigam. Assim, o trabalho desenvolvido no interior destas é organizado visando garantir o máximo de segurança, não apenas para seus funcionários e moradores que circundam a área fabril, mas também para o meio ambiente de maneira restrita e ampla. Cabe ressaltar que o significado do risco industrial não é o mesmo para gestores, funcionários e a vizinhança, uma vez que a relação cotidiana com a indústria e com o risco são específicas de cada um desses grupos, assim, as ameaças não são necessariamente vistas como tais, embora estejam presentes. (VEYRET, 2007)

Diante do exposto, pode-se aferir que o teor de periculosidade destes resíduos per $s i$, já criam uma situação de vulnerabilidade e risco, independentemente da existência ou não de acidentes. Partindo desta situação factual, algumas reflexões sobre a situação dos resíduos sólidos industriais foram levantadas: Que tipo de tratamento é dado aos resíduos sólidos perigosos produzidos nas indústrias? Qual a sua destinação final? Qual a intensidade e nível de exposição à situações riscos, estão expostos os atores sociais envolvidos no processo de produção industrial?

Buscando dar concretude a estas reflexões, vem sendo desenvolvida uma pesquisa no distrito industrial de Maracanaú-Ceará-Brasil, com o objetivo maior de analisar os riscos socioambientais e as vulnerabilidades decorrentes da gestão dos resíduos sólidos industriais perigosos.

Características de inflamabilidade, corrosividade, reatividade, toxicidade e patogenicidade. 


\section{TRAJETÓRIA METODOLÓGICA}

De modo geral, a metodologia aplicada teve como base os trabalhos de campo para o reconhecimento da área da pesquisa, bem como coleta de dados, informações e imagens da área, constando ainda da aplicação de questionários e entrevistas com representantes das indústrias, comunidade e de órgãos públicos.

Inicialmente, realizou-se o levantamento das indústrias, usando informações no Guia Industrial do Ceará 2012-1013, documento produzido pela Federação das Indústrias do Estado do Ceará (FIEC). Foram selecionadas, previamente, 46 indústrias, tendo como critérios, o processo produtivo, a grande geração de resíduos classe I e o número de funcionários ( $\geq$ de 30 funcionários). Diante da recusa das indústrias em fornecer informações referentes a gestão dos resíduos perigosos gerados, o total de indústrias pesquisadas resultou em 20 (vinte), ou seja, menos da metade primeiramente levantadas.

Deste modo, as informações referentes a quantificação do volume dos resíduos industriais perigosos, classe I, gerados no município de Maracanaú, se deu através de consulta dos Planos de Gerenciamento de Resíduos Sólidos, enviados pelas indústrias a Superintendência de Meio Ambiente do Ceará - SEMACE, ou seja, tiveram como base dados secundários. Vale destacar que a permissão para o levantamento dos mesmos teve como premissa a condição de manter em sigilo o nome das indústrias inventariadas.

\section{DISCUSSÃO TEÓRICA E RESULTADOS}

A problemática ambiental intensificou-se com a revolução industrial, as pesquisas tecnológicas ocorridas nesse período contribuíram para modernizar o modo de produção fabril elevando a extração de recursos naturais a níveis comprometedores ao equilíbrio natural. A ampliação da expectativa de vida, através dos avanços da medicina preventiva e sanitária, acarretou, por conseguinte, o crescimento demográfico, e este, o aumento do consumo. Aproveitando- se do contexto e visando obter mais lucros, os donos das indústrias investiram em novas técnicas de produção em massa, com o intuito de atender a demanda cada vez mais crescente de consumo.

A incorporação de novos hábitos de consumo, e o aprimoramento de técnicas cada vez mais modernas de industrialização, acarretaram um aumento significativo no volume de resíduos gerados e dos impactos ambientais adversos decorrentes da produção destes.

Destarte, cerca de dois séculos após o advento da revolução industrial, a gestão dos resíduos sólidos permanece como um dos grandes desafios da sociedade contemporânea. Segundo Jacobi (2011a) desde a Rio 92, a gestão sustentável de resíduos sólidos represen- 
ta uma mudança paradigmática, que tem direcionado a atuação dos governos, da sociedade e da indústria.

No caso do Brasil o desafio da gestão dos resíduos sólidos é hercúleo, principalmente no que se refere a destinação final, pois 42,02\% dos resíduos sólidos urbanos coletados no país são dispostos de maneira inadequada (ABRELPE, 2012). Seja por não dispor do conjunto de técnicas necessárias à preservação ambiental e a mitigação dos impactos negativos derivados do manejo incorreto, seja pelo descaso à proteção da saúde da população.

Diante de tal realidade, a pressão da opinião pública, de grupos ambientalistas e associações de catadores, vem exigindo crescentes cuidados com esses impactos sobre o meio ambiente. A promulgação da Política Nacional de Resíduos Sólidos (PNRS) em 2010, Lei 12.305, foi uma das conquistas obtidas e trouxe vários avanços no que se refere a gestão dos resíduos sólidos no Brasil. Entre estes destacam-se: a abordagem sistêmica, logística reversa, responsabilidade compartilhada, ênfase na redução e reutilização dos resíduos, educação ambiental, o reconhecimento e inclusão do catador com ator social.

É inegável a importância da PNRS, considera-se até que demorou demais a sair, entretanto as metas propostas geraram uma certa tensão entre sociedade civil, governos municipais, estaduais e governo federal. Principalmente a da erradicação dos lixões até agosto 2014, os quais deverão ser substituídos por aterros sanitários, para onde os resíduos recicláveis não poderão ser enviados.

As prefeituras alegam não possuírem condições econômicas para atingirem a meta estabelecida, consequentemente, grande parte dos municípios encontram-se hoje em situação de descumprimento da legislação.

Vale frisar que o acesso aos recursos financeiros destinados às mudanças estabelecidas pela lei são de âmbito federal e está atrelado a apresentação de planos de gerenciamento de resíduos sólidos (PGRS) por parte das três esferas governamentais - municipal, estadual e federal. No estado do Ceará o Plano Estadual de Resíduos Sólidos (PERS) encontra-se em fase de elaboração e os municípios estão tentando elaborar ainda os Planos Municipais de Saneamento Básico (PMSB) exigidos pela Lei do Saneamento Básico (Lei $\left.n^{\circ} 11.445 / 2007\right)$, anterior à Lei 12.305/2010.

Em relação aos PMSB, segundo a FUNASA² e a $\mathrm{ARCE}^{3}$, em 2012 existiam cinco planos elaborados (Morada Nova, Limoeiro do Norte, Iguatu, Cariús e Quixelô), correspondente a 3\% dos 184 municípios cearenses. 65 planos estão em andamento (35\% da deman- 
da); 18 municípios estão em análise pela FUNASA para financiamento (10\% da demanda); $52 \%$ do total de municípios não possuem planos encaminhados, ou seja, 96 deles. O contexto revela que as prefeituras estão tendo dificuldade de fazer o PMSB e já se veem cobradas a elaborarem o Plano Municipal de Resíduos Sólidos (PMRS).

Em grande medida, as legislações e regulamentações brasileiras propostas para o gerenciamento de resíduos são caracterizadas por uma definição geral de resíduos sólidos, o que amiúde, confunde o entendimento conceitual e evidencia a diversidade e complexidade da temática.

Como se pode ver no Art. $3^{\circ}$ da Política Nacional de Resíduos Sólidos, que os define como:

XVI - resíduos sólidos: material, substância, objeto ou bem descartado resultante de atividades humanas em sociedade, a cuja destinação final se procede, se propõe proceder ou se está obrigado a proceder, nos estados sólido ou semissólido, bem como gases contidos em recipientes e líquidos cujas particularidades tornem inviável o seu lançamento em rede pública de esgotos ou de corpos d'água, ou exijam para isso soluções técnica ou economicamente inviáveis em face da melhor tecnologia disponível. (2010, p.03)

Nesse mesmo viés, a ABNT NBR 10004/04, que classifica os resíduos sólidos quanto aos riscos potenciais ao meio ambiente e à saúde pública considera,

Resíduos sólidos: Resíduos nos estados sólido e semi-sólido, que resultam de atividades de origem industrial, doméstica, hospitalar, comercial, agrícola, de serviços e de varrição. Ficam incluídos nesta definição os lodos provenientes de sistemas de tratamento de água, aqueles gerados em equipamentos e instalações de controle de poluição [...]. (2014, p.07)

Observa-se que ambas definições de resíduos sólidos, comporta os estados semissólido, líquido e até mesmo gasoso, fato que dificulta, muitas vezes, sua compreensão por parte dos leigos e de algumas pessoas que sobrevivem do manejo desse material descartado. Sem falar que para maioria da população a palavra resíduo é usualmente utilizada como sinônimo de lixo, "coisa que se varre da casa, da rua, e se joga fora" (FERREIRA, 2001, p.462).

Há outras situações em que a conceituação destes resíduos é equivalente à de rejeitos, "resíduos sólidos que, depois de esgotadas todas as possibilidades de tratamento e recuperação por processos tecnológicos disponíveis e economicamente viáveis, não apresentem outra possibilidade que não a disposição final ambientalmente adequada ${ }^{4 \prime}$. (PNRS, 2010, p.02)

\footnotetext{
4 De acordo com a Lei 12.305, disposição final ambientalmente adequada é a distribuição de rejeitos em aterros observando normas operacionais específicas de modo a evitar danos ou riscos à saúde pública e à segurança e a minimizar os impactos ambientais adversos.
} 
Para uma melhor compreensão das análises e discussões realizadas no corpo do presente trabalho, é pertinente esclarecer que o termo resíduo sólido será aqui entendido como, todo material sólido e semissólido resultante de atividades humanas (industrial, doméstica, hospitalar, comercial, agrícola, de serviços e de varrição) descartados no meio ambiente devido sua prévia inutilidade.

No que concerne à classificação, os resíduos se diferem conforme sua natureza física (seco, molhado); composição química (orgânico, inorgânico); riscos potenciais ao meio ambiente e à saúde pública (perigosos, não perigosos) e a origem (domiciliar, urbano, comercial, público, industrial, serviços de saúde, construção civil, agrossilvopastoril, serviços de transporte e mineração).

Decerto, a classificação multifacetária de resíduos transcende o objetivo desta pesquisa, deste modo, é oportuno elucidar que a explicitação pormenorizada, a seguir, dos resíduos que oferecem riscos potenciais ao meio ambiente e à saúde pública e dos resíduos industriais, deve-se a sua condição de categoria basilar do presente estudo.

Considerando a crescente preocupação da sociedade com relação às questões ambientais e a gestão dos resíduos, a Associação Brasileira de Normas Técnicas - ABNT - criou em 1987 uma norma específica para classificá-los, a NBR 10004 (atualizada em 2004), visando fornecer subsídios para o gerenciamento adequado dos mesmos.

Nesse sentido, a classificação dos resíduos sólidos, trazida nesta Norma, envolve uma identificação criteriosa do processo ou atividade que lhes deu origem e de seus constituintes e características e a comparação destes constituintes com listagens de resíduos e substâncias cujo impacto à saúde e ao meio ambiente é conhecido. A segregação dos resíduos na fonte geradora é parte integrante dos laudos de classificação, onde a descrição de matérias-primas, de insumos e do processo no qual o resíduo foi gerado devem ser explicitados. (NBR 10004)

Segundo a NBR 10004:04, quanto à periculosidade os resíduos são assim classificados:

1. Resíduos classe I, considerados perigosos em função de suas propriedades físicas, químicas ou infecto-contagiosas, pode apresentar: a) risco à saúde pública, provocando mortalidade, incidência de doenças ou acentuando seus índices; b) riscos ao meio ambiente, quando o resíduo for gerenciado de forma inadequada

2. Resíduos classe II, considerados não perigosos em função de não apresentar riscos à saúde pública e ao meio ambiente. São divididos em: 
a. Resíduos classe II A - Não inertes, aqueles que não se enquadram nas classificações de resíduos classe I ou resíduos classe II B, podendo ter propriedades como biodegradabilidade, combustibilidade ou solubilidade em água.

b. Resíduos classe II B - Inertes, aqueles que quando submetidos a um contato com água destilada ou desionizada, à temperatura ambiente, não tem nenhum de seus constituintes solubilizados a concentrações superiores aos padrões de potabilidade de água, excetuando-se aspecto, cor, turbidez, dureza e sabor.

A identificação e classificação, é parte integrante da etapa inicial do gerenciamento de resíduos sólidos, composto pelas etapas de coleta, transporte, transbordo, tratamento e destinação final ambientalmente adequada. Por sua vez, o gerenciamento corresponde a uma parte da gestão integrada dos resíduos sólidos, a qual engloba as dimensões política, econômica, ambiental, cultural e social da questão, sob a premissa do desenvolvimento sustentável. (PNRS, 2010)

\section{Figura 1 - Gestão de Resíduos Sólidos Ambientalmente Adequada de Resíduos Sólidos}

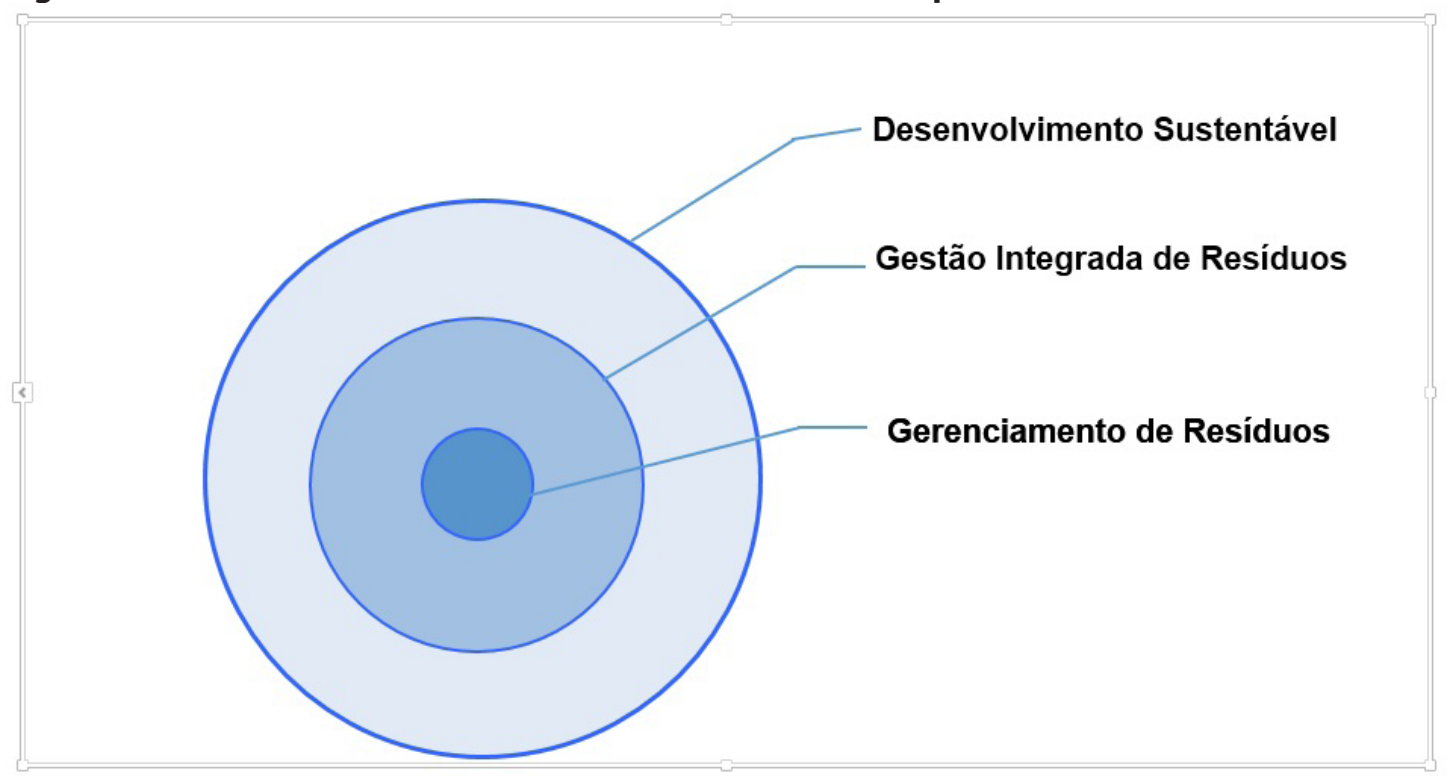

Fonte: Elaboração da autora a partir de PNRS - 2013

$\mathrm{Na}$ forma da Lei 12.305, o gerenciamento e a gestão integrada dos resíduos sólidos deve seguir à ordem de prioridade: não geração, redução, reutilização, reciclagem, tratamento dos resíduos sólidos e destinação final ambientalmente adequada dos rejeitos.

No tocante a definição dos resíduos industriais, a Política Nacional de Resíduos Sólidos, os define resumidamente como, os "gerados nos processos produtivos e instalações industriais."(2010, p.7).

a 
Já o Instituto de Pesquisas Tecnológicas (IPT) os conceitua de forma mais específica:

Aquele originado nas atividades dos diversos ramos da indústria, tais como metalurgia, química, petroquímica, papeleira, alimentícia, etc. O lixo industrial é bastante variado, podendo ser representado por cinzas, lodos, óleos, resíduos alcalinos ou ácidos, plásticos, papéis, madeiras, fibras, borrachas, metais, escórias, vidros e cerâmicas. Nesta categoria, inclui-se a grande maioria do lixo considerado tóxico (Classe I). (2000, p.30).

Em contribuição mais recente Waldman (2010) complementa, os resíduos industriais são produzidos na extração e transformação de matérias primas, abrangendo às atividades mineradoras e de obtenção de energia, inclusive a nuclear. Devido sua singularidade, exigem descarte específico, não apenas o volume, mas a periculosidade é outro fator de risco.

Com base no exposto, pode-se afirmar que a grande maioria dos resíduos industriais contém substâncias tóxicas. Diversos produtos utilizados no processo produtivo industrial possuem metais pesados, nocivos tanto ao meio ambiente quanto à saúde pública. Estes, diferem de outros agentes tóxicos porque não são sintetizados nem destruídos pelo homem, ou seja, acumulam-se no organismo que é incapaz de eliminá-los, se ligam às paredes celulares dificultando o transporte de nutrientes o que pode ocasionar até à morte.

Um detalhamento da tipificação dos resíduos classe I gerados pelas indústrias de Maracanaú pode ser verificado na tabela 01, especialmente no que se refere a identificação dos constituintes perigosos a serem avaliados com a finalidade de estabelecer seu potencial de risco à saúde humana e ao meio ambiente.

Tabela 1 - Resíduos Classe I Inventariados por Código do Conama 313

\begin{tabular}{c|lc|c}
$\begin{array}{c}\text { Cód. } \\
\text { Resíduo } \\
\text { Classe I }\end{array}$ & \multicolumn{1}{c|}{ Descrição do Resíduo } & $\begin{array}{c}\text { Constituinte } \\
\text { Perigoso }\end{array}$ & Periculosidade \\
D099 & Outros resíduos perigosos - especificar & Não aplicável & Tóxico \\
\hline F044 & $\begin{array}{l}\text { Lâmpada com vapor de mercúrio após } \\
\text { O uso }\end{array}$ & Mercúrio & Tóxico \\
\hline F104 & $\begin{array}{l}\text { Embalagens vazias contaminadas não } \\
\text { especificados na Norma NBR 10.004 }\end{array}$ & Não aplicável* & Tóxico \\
\hline F105 & $\begin{array}{l}\text { Solventes contaminados (especificar o sol- } \\
\text { vente e o principal contaminante) }\end{array}$ & Solvente & Inflamável \\
\hline F130 & Óleo lubrificante usado ou contaminado & Não aplicável* & Tóxico \\
\hline F230 & Fluido e óleo hidráulico usado & Não aplicável* & Tóxico \\
\hline K053 & Restos e borras de tintas e pigmentos & $\begin{array}{c}\text { Cromo, chumbo } \\
\text { hexavalente }\end{array}$ & Tóxico \\
\hline
\end{tabular}

K193 Aparas de couro provenientes de couros curtidos ao cromo

Cromo hexavalente

Tóxico 


\begin{tabular}{|c|c|c|c|}
\hline $\begin{array}{l}\text { Cód. } \\
\text { Resíduo } \\
\text { Classe I }\end{array}$ & Descrição do Resíduo & $\begin{array}{l}\text { Constituinte } \\
\text { Perigoso }\end{array}$ & Periculosidade \\
\hline K194 & $\begin{array}{l}\text { Serragem e pós de couro provenientes } \\
\text { de couros curtidos ao cromo }\end{array}$ & Cromo hexavalente & Tóxico \\
\hline K195 & $\begin{array}{l}\text { Lodos provenientes do tratamento de } \\
\text { efluentes líquidos originados no proces- } \\
\text { so de curtimento de couros ao cromo }\end{array}$ & Cromo hexavalente & Tóxico \\
\hline K207 & $\begin{array}{l}\text { Borra do re-refino de óleos usados } \\
\text { (borra ácida) }\end{array}$ & Não aplicável* & Tóxico \\
\hline K209 & $\begin{array}{l}\text { Poeiras provenientes do sistema de con- } \\
\text { trole de emissão de gases empregado } \\
\text { nos fornos Cubilot empregados na fun- } \\
\text { dição de ferro }\end{array}$ & $\begin{array}{l}\text { Cromo, chumbo, } \\
\text { arsênio }\end{array}$ & Tóxico \\
\hline K210 & Casca da castanha de caju & $\begin{array}{l}\text { Chumbo, cádmio, } \\
\text { cromo }\end{array}$ & Tóxico \\
\hline K213 & $\begin{array}{l}\text { Estopas contaminadas com óleos e/ } \\
\text { ou graxas }\end{array}$ & Não aplicável* & Reativo \\
\hline K214 & Pilhas e Baterias em geral & $\begin{array}{l}\text { Chumbo, cádmio, } \\
\text { mercúrio }\end{array}$ & $\begin{array}{l}\text { Inflamável } \\
\text { tóxico }\end{array}$ \\
\hline $\begin{array}{l}\text { CONAMA } \\
358\end{array}$ & $\begin{array}{l}\text { Tratamento e a disposição final dos resíduos } \\
\text { dos serviços de saúde }\end{array}$ & Não aplicável* & Tóxico \\
\hline
\end{tabular}

*Não aplicável - termo empregado quando o resíduo enquadra-se como perigoso pela presença de um grande número de constituintes perigosos ou pelo efeito conjunto destes.

Fonte: Elaboração da autora a partir do CONAMA 313 e NBR 10004.

A presença desses metais, muitas vezes, está associada à localização geográfica de áreas urbanas e/ou industriais. Os despejos de resíduos industriais na natureza são as principais fontes de contaminação e poluição ambiental. Quando lançados como resíduos, na água, no solo ou no ar, podem ser absorvidos por vegetais e animais, provocando graves intoxicações ao longo da cadeia alimentar. Cabe ressaltar que todas as formas de vida do planeta podem ser afetadas pela presença desses metais, dependendo da dosagem e da forma química. (NAKANO et CAMPOS, 2013)

Metais pesados estão presentes na linha de produção de várias indústrias, tais como indústrias extrativistas de metais, de tintas e pigmentos, beneficiamento de couro, indústrias de ferro e aço, lavanderias, indústria de petróleo, e, especialmente, as galvanoplastias, que se espalham vertiginosamente nas periferias das grandes cidades. Outra fonte potencial de contaminação do ambiente por metais pesados são os incineradores de resídu- 
os urbano e industrial, que provocam a sua volatização e formam cinzas ricas em metais, principalmente mercúrio, chumbo e cádmio.

No tocante a Maracanaú, a título de exemplificação cumpre observar que as indústrias de plástico, beneficiamento de couro e cerâmica são as principais geradoras de resíduos classe I, respondendo juntas por $75,64 \%$ do total de resíduos gerados. Os setores elétrico, asfalto e de alimento são os menores geradores com cerca de $0,13 \%$ os três. As demais indústrias somam $24,22 \%$, conforme demonstrado na tabela 02.

Tabela 2 - Resíduos Sólidos Classe I por Indústria/Atividade - 2013

\begin{tabular}{|c|c|c|c|}
\hline No ORDEM & INDÚSTRIAS & ATIVIDADE & t/mês \\
\hline 1 & A & Alimento & 0,282 \\
\hline 2 & B & Alimento & 0,338 \\
\hline 3 & C & Bebida & 4,666 \\
\hline 4 & D & Beneficiamento de Couro & 79,156 \\
\hline 5 & E & Elétrico & 0,027 \\
\hline 6 & F & Metalurgia & 17,309 \\
\hline 7 & G & Metalurgia & 15,544 \\
\hline 8 & $\mathrm{H}$ & Metalurgia & 2,5 \\
\hline 9 & 1 & Têxtil & 0,009 \\
\hline 10 & J & Têxtil & 11,665 \\
\hline 11 & L & Têxtil & 0,02 \\
\hline 12 & M & Químico & 4,072 \\
\hline 13 & $\mathrm{~N}$ & Tratamento de Resíduos & 8,502 \\
\hline 14 & $\mathrm{O}$ & Tintas & 6,282 \\
\hline 15 & $P$ & Cerâmica & 61 \\
\hline 16 & Q & Plástico & 108,333 \\
\hline 17 & $\mathrm{R}$ & Colchões & 0,691 \\
\hline 18 & $S$ & Celulose & 7,89 \\
\hline 19 & T & Asfalto & 0,018 \\
\hline 20 & U & Asfalto & 0,198 \\
\hline
\end{tabular}

TOTAL

Fonte: Elaboração da autora a partir de dados da FIEC/SEMACE-2013 
Foram identificados 15 tipos de resíduos perigosos gerados pelas indústrias (quadro 01), o F230 - Fluido e óleo hidráulico usado - é o gerado em maior quantidade (33\%), seguido pelo K053 - Restos e borras de tintas e pigmentos - com 28\% e o K195 - Lodos provenientes do tratamento de efluentes líquidos originados no processo de curtimento de couros ao cromo - 17,1\%. Cabe destacar que o K053 e K195 têm em comum o constituinte cromo hexavalente, reconhecido como um carcinogênico humano. Os outros resíduos correspondem a $22 \%$.

Quadro 1 - Quantidade de Resíduos Classe I Inventariados - 2013

\begin{tabular}{|c|c|c|c|}
\hline No Ordem & Resíduo Conama 313 & t/mês & $\%$ \\
\hline 1 & D099 & 12,215 & 3,7 \\
\hline 3 & F044 & 0,018 & 0 \\
\hline 4 & F104 & 11,331 & 3,4 \\
\hline 5 & F105 & 1,871 & 0,5 \\
\hline 6 & F130 & 4,985 & 1,6 \\
\hline 7 & F230 & 108,333 & 33 \\
\hline 8 & K053 & 91,449 & 28 \\
\hline 9 & K193 & 11,391 & 3,5 \\
\hline 10 & K194 & 5,19 & 1,5 \\
\hline 11 & K195 & 56,265 & 17,1 \\
\hline 12 & K207 & 0,582 & 0,2 \\
\hline 13 & K209 & 14,496 & 4,4 \\
\hline 14 & K213 & 10,297 & 3,1 \\
\hline 15 & K214 & 0,013 & 0 \\
\hline 16 & CONAMA 358 & 0,066 & 0 \\
\hline \multicolumn{2}{|c|}{ TOTAL } & 328,502 & 100 \\
\hline
\end{tabular}

A forma como estes resíduos são armazenados nas indústrias, e sua destinação final estão demonstradas na tabela 03. Observa-se que o aterro classe I, que aparece na tabela, está localizado no estado de Pernambuco, cabe lembrar a inexistência de aterro classe I no Ceará, fato que corrobora com a destinação final inadequada destes resíduos. Percebe-se que muitos destes resíduos têm destinação inadequada, como por exemplo, o Aterro Sanitário Metropolitano Oeste de Caucaia - ASMOC, destinado aos resíduos sólidos urbanos, classificados como não perigosos (classe II). Quanto ao armazenamento, percebe-se 
que não há uma homogeneidade entre as indústrias para o armazenamento de um mesmo resíduo, como é o caso dos resíduos D099, F044, F104, dentre outros.

Tabela 3 - Armazenamento e Destinação Final dos Resíduos Classe I

\begin{tabular}{|c|c|c|}
\hline RESÍDUOS & ARMAZENAMENTO & DESTINAÇÃO FINAL \\
\hline D099 & $\begin{array}{l}\text { Tambor metálico, área coberta, baias cober- } \\
\text { tas, a granel, depósito de resíduos perigosos }\end{array}$ & $\begin{array}{l}\text { Coprocessamento, reciclagem, } \\
\text { ASMOC* }^{*} \text { incineração }\end{array}$ \\
\hline F044 & $\begin{array}{l}\text { Caixa de madeira baias, tambor c/ tampa } \\
\text { em galpão coberto c/ piso impermeável, } \\
\text { baias, caixa de madeira, Depósito de resí- } \\
\text { duos perigosos }\end{array}$ & $\begin{array}{l}\text { Descontaminação - empresa } \\
\text { especializada }\end{array}$ \\
\hline F104 & $\begin{array}{l}\text { Área coberta, baias, a granel em galpão co- } \\
\text { berto c/ piso impermeável, galpão coberto, } \\
\text { Conteiner, a granel }\end{array}$ & $\begin{array}{l}\text { Reciclagem, ASMOC, } \\
\text { coprocessamento }\end{array}$ \\
\hline F105 & Conteiner plástico & Empresa especializada \\
\hline
\end{tabular}

\begin{tabular}{lll}
\hline \multirow{2}{*}{ F130 } & Tambor em área coberta c/ piso impermeável, & Empresa especializada, reciclagem, \\
baias, Tambor c/ tampa - área externa, área de & ASMOC, coprocessamento, \\
resíduo da fábrica, tambor/bombona, a granel & rerefino, SEMACE
\end{tabular}

\begin{tabular}{cll}
\hline F230 & $\begin{array}{l}\text { Galpão coberto, galpão coberto c/ piso im- } \\
\text { permeável }\end{array}$ & Rerefino, reciclagem \\
\hline K053 & $\begin{array}{l}\text { Conteiner coberto, galpão coberto, baias, } \\
\text { tambor c/ tampa - área externa }\end{array}$ & $\begin{array}{l}\text { Aterro classe I - PE, } \\
\text { reutilizado na própria } \\
\text { empresa, reciclagem, ASMOC, } \\
\text { coprocessamento, rerefino }\end{array}$ \\
\hline K193 & Área coberta c/ piso impermeável & Aterro classe I - PE \\
\hline K194 & Área coberta c/ piso impermeável & Aterro classe I - PE \\
\hline K195 & Caçamba c/ cobertura & ASMOC \\
\hline K207 & Galpão coberto & Coprocessamento \\
\hline
\end{tabular}

K209 Big Bag - galpão coberto c/ piso impermeável Coprocessamento

\begin{tabular}{cll}
\hline K213 & $\begin{array}{l}\text { Tambor metálico, baias, Tambor c/ tampa }- \\
\text { área externa, galpão coberto, tambor de plás- } \\
\text { tico, tambor fechado }\end{array}$ & $\begin{array}{l}\text { Coprocessamento, empresa } \\
\text { especializada, incineração }\end{array}$ \\
\hline K214 & $\begin{array}{l}\text { Não informado, Big Bag - galpão coberto c/ } \\
\text { piso impermeável }\end{array}$ & $\begin{array}{l}\text { Reciclagem, ASMOC, } \\
\text { coprocessamento, devolvido ao } \\
\text { fabricante ou disposto em PEV }\end{array}$ \\
\hline
\end{tabular}
Tambor c/ tampa - área externa, galpão co- Conama 358 berto, área de resíduo da fábrica, bombona de plástico, tambor/bombona, conteiner, conteiner fechado Coprocessamento, incineração

*ASMOC - Aterro Sanitário Metropolitano Oeste de Caucaia Fonte: Elaboração da autora a partir de dados da - FIEC/SEMACE -2013 
De acordo com a Associação Brasileira de Empresas de Tratamento, Recuperação e Disposição de Resíduos Especiais (ABETRE), dos 2,9 milhões de toneladas de resíduos industriais perigosos gerados anualmente no Brasil, somente 600 mil toneladas recebem tratamento adequado (coprocessamento, incineração, aterro classe I). Os 78\% restantes são depositados indevidamente em lixões, sem qualquer tipo de tratamento. (apud, Nakano, 2013)

A legislação promulga que a responsabilidade pelo armazenamento, transporte, tratamento e destinação adequada dos resíduos industriais é do gerador. A explicitação dessa competência permite dirimir qualquer dúvida sobre o responsável no caso de ocorrência de acidentes, obrigando-o arcar com os custos de recuperação ou de medidas mitigadoras, referente a um ato prejudicial ao meio ambiente e/ou à saúde da população.

Esta preocupação legal em definir o responsável por um dano causado ao meio ambiente ou a população, é decorrente de um processo de luta da sociedade civil frente aos grandes desastres ambientais ocorridos no século XX, entre os mais conhecidos, Minamata-Japão (1956), Seveso - Itália (1976), Bophal-Índia (1984).

De origem industrial, esses acidentes chamaram à atenção para os riscos reais da poluição ambiental na qualidade de vida e na sobrevivência da espécie humana, mostrando a necessidade de se prevenir quanto a sua ocorrência e seus efeitos de curto e longo prazos. Abordando a questão com uma maior amplitude, Beck (2010) postula que os riscos fabris são produtos da modernidade, que se revelam sob a forma de ameaças à vida de plantas, animais e seres humanos.

De maneira geral, o risco sempre transitou na história da humanidade, se fez e faz presente nos momentos de perigo e nas sensações de ameaça e incerteza, podendo ser vinculado à ações naturais ou humanas. Entretanto, com a industrialização e seus efeitos, contrários ao equilíbrio ambiental, as situações de riscos tomaram proporções gigantescas, onde muitas vezes, ações de defesa e prevenção são ineficazes.

Beck, ilustra bem a ideia aqui apresentada.

Contra as ameaças da natureza externa, aprendemos a construir cabanas e a acumular conhecimentos. Diante das ameaças da segunda natureza, absorvida no sistema industrial, vemo-nos praticamente indefesos. Perigos, vêm a reboque do consumo cotidiano. (2005, p.9).

Considera-se que a citação do autor "abre caminho" para a discussão de dois elementos fundamentais do presente trabalho, risco industrial, e os perigos resultante do consumo. Nas palavras de Jacobi (2006b), o atendimento das necessidades de consumo exige uma diversidade cada vez maior de produtos, que acabam gerando resíduos, seja no processo de produção ou após o seu consumo e com diferentes graus de periculosidade. 
Conforme Veyret (2007), diferente do risco natural, familiar aos geógrafos, o risco industrial foi inicialmente estudado por engenheiros, a partir de uma análise matemática entre probabilidade/consequência ou frequência/gravidade, que permitiu quantificar o risco e definir os níveis de aceitabilidade. Entretanto, uma avaliação profunda da questão não deve se restringir à abordagem puramente tecnicista, a incerteza que há numa situação de risco advém de fatores geográficos ou humanos, dificilmente modeláveis.

Fica patente que, “o risco é certamente, um objeto geográfico. É preciso por tanto, tratá-lo em termos espaciais. Ele se situa na interface entre um espaço industrial e espaços urbanos (ou rurais) que o englobam.” (VEYRET, 2007, p. 180).

A avaliação normativa de risco industrial o distingue em dois tipos: risco individual e risco social. O risco individual tem caráter cumulativo e geográfico, ou seja, leva-se em consideração o risco existente para um indivíduo na vizinhança de um perigo, em período de tempo definido. O risco social é considerado para um agrupamento de pessoas presente na vizinhança de um perigo, em período de tempo definido. (CETESB, 2011).

Em ambas definições, tanto o indivíduo quanto o grupo estão expostos à situação de risco em determinado espaço (vizinhança) e período temporal, esta realidade os coloca numa posição de vulnerabilidade. Para Hewitt (1997, apud CASTRO, 2005), as situações de risco (risk) e de segurança (safety) são decorrentes de uma tríade de elementos: os perigos (hazards), a vulnerabilidade e a intervenção e adaptação às condições de perigo.

Apresentando posição similar, Moser (1998) reconhece que, a exposição ao risco é um dos componentes presentes em situações de vulnerabilidade, assim como, a incapacidade de reação, e a dificuldade de adaptação diante da materialização do risco. (apud ALVES, 2006).

A capacidade de resposta e dificuldade de adaptação diante da concretude do risco, está diretamente relacionada a uma gama de recursos: ambientais, técnicos, humanos, econômicos, sociais e políticos. Entretanto, vale advertir que, os "fatores socioeconômicos frequentemente aumentam a vulnerabilidade das populações ameaçadas" (VEYRET, 2007, p.40).

Considera-se que a adaptação às condições de risco, aprioristicamente passa pela aceitação, que por sua vez só é possível existir se houver confiança. Para Castro (2005), no caso dos riscos naturais, a relação confiança e risco é menor, a menos que esteja envolvida nesta relação alguma forma de controle humano (trabalho/tecnologia) sobre os perigos, fato que demanda confiança da sociedade (leiga) ao sistema de controle implementado tendo ou não consciência do perigo ao qual se encontra exposto. Presume-se então que no caso dos riscos relacionados às ações humanas, a relação confiança e risco seja maior. 
Segundo Slovic (1998, apud, CASTRO, 2005), a falta de confiança é cada vez mais apontada como um fator crítico e implícito nas discussões que envolvem a gestão de resíduos, principalmente os tecnológicos. Talvez, devido ser tão comumente utilizada no cotidiano, sua importância para a gestão de riscos ainda não tenha sido devidamente valorizada.

Balizado nas colocações supracitadas, o termo confiança adentra nos questionamentos aqui levantados. Qual o nível de risco existente nos resíduos industriais? Há confiança de que as indústrias estão fazendo o manejo dos resíduos perigosos de forma adequada? Quase medidas de segurança estão sendo tomadas? Até que ponto se pode confiar nas precauções tomadas pelas indústrias quanto ao risco advindo do manejo dos resíduos-classe I?

\section{UMA OUTRA REVOLUÇÃO INDUSTRIAL}

O processo de industrialização do Ceará é recente, remonta aos investimentos efetuados pela Superintendência de Desenvolvimento do Nordeste - SUDENE, nas décadas de 1960 e 1970. Como apontado por estudos históricos realizados por Farias (2009), foi no governo de Virgílio Távora, 1963 a 1966, que pela primeira vez no Ceará foi organizado um plano de ação governamental baseado nos planos de metas desenvolvimentistas nacionais do governo Kubistcheck e no Plano Trienal de João Goulart.

Nesse contexto foi criado primeiro Plano de Metas Governamentais (PLAMEG I) do Ceará, constituído por uma série de medidas econômicas e administrativas a serem aplicadas pelo governo, visando prioritariamente a industrialização cearense e à ascendência no cenário industrial nacional.

Para tal empreitada foram realizadas diversas obras de infraestrutura (redes de energia, transporte e comunicação), financiadas com recursos de instituições internacionais como o Banco Internacional de Desenvolvimento (BID) e a Aliança Para o Progresso (programa governamental norte americano contrário às esquerdas latinas), e de órgãos federais como a SUDENE e o Banco do Nordeste do Brasil - BNB. Datam deste governo, a criação da Companhia Docas do Ceará; a Fábrica de Asfalto do Mucuripe; uma linha de transmissão de energia da usina de Paulo Afonso e a criação do I Distrito Industrial em Maracanaú - DI (FARIAS, 2009). A inauguração do DI de Maracanaú ocorrida em março de 1966 contou com a presença de seu cearense mais ilustre, o então presidente da república, Humberto Castelo Branco.

Conforme pesquisa geográfica realizada por Carvalho(2009), a criação do I Distrito Industrial de Maracanaú, beneficiado por incentivos fiscais, surge visando cumprir um plano político com um aporte estrutural capaz de sustentar um grande contingente indus- 
trial. Entretanto, inicialmente, não atraiu o quantitativo de indústrias esperado, pelo fato de apresentar, naquele momento, uma gama de deficiências estruturais não condizentes com os padrões exigidos pelas indústrias de grande porte, para sua implantação, apesar dos benefícios fiscais oferecidos.

A otimização do polo industrial só veio ocorrer duas décadas após sua criação, mas nem por isso pode ser considerada menos avassaladora. Como apontado por Mourão e Cavalcante (2006), no curto intervalo que vai de 1970 a 1990, Maracanaú passou de um cidadezinha com características rurais para uma cidade eminentemente industrial.

Por conseguinte, é possível considerar que a complexidade característica do processo produtivo industrial foi incorporada ao espaço maracanauense até então existente. Entretanto, vale advertir, apresentando argumento de Santos (1988), que uma variável externa só é capaz de se integrar a um local, se este possuir internamente as condições para poder aceitá-la, ou seja, a internalização do externo não se dá à revelia, mas a partir da combinação entre variáveis externas e internas que darão origem a um outro arranjo espacial.

A política de incentivos governamentais proporcionou a Maracanaú as condições internas necessárias à implantação de um polo industrial em seu território. Em sua página da internet ${ }^{5}$ a prefeitura expõe uma série de incentivos direcionados às indústrias que desejam ali instalar-se, como por exemplo: redução de impostos municipais (ISS e IPTU), doação de terrenos e subvenção de locação de galpões, além de mencionar a parceria com o Governo do Estado para disponibilização de infraestrutura adequada até o limite do terreno do empreendimento.

Atualmente o município de Maracanaú possui três distritos industriais ${ }^{6}$ (DIF I, DIF III e DI 2000) os quais concentram 100 indústrias ${ }^{7}$ atuando em diversas atividades produtivas, como têxtil, beneficiamento de couro, metalurgia e mecânica, papel e papelão, alimento, elétrico, químico e de tintas.

5 www.maracanaú.ce.gov.br

6 A prefeitura de Maracanáu considera também a existência de mais dois DIs, o distrito industrial do Alto Alegre II com 02 indústrias instaladas e o distrito industrial de Piratininga sem indústrias instaladas, até o momento. Devido da incipiente quantidade de indústrias instaladas, não irão compor o universo da pesquisa.

7 O conceito de indústria refere-se à atividade de produção de mercadorias, desconsiderando assim os estabelecimentos que se restringe à comercialização dos produtos manufaturados. 
Figura 2 - Distribuição das Indústrias de Maracanaú por Distritos industriais (\%)

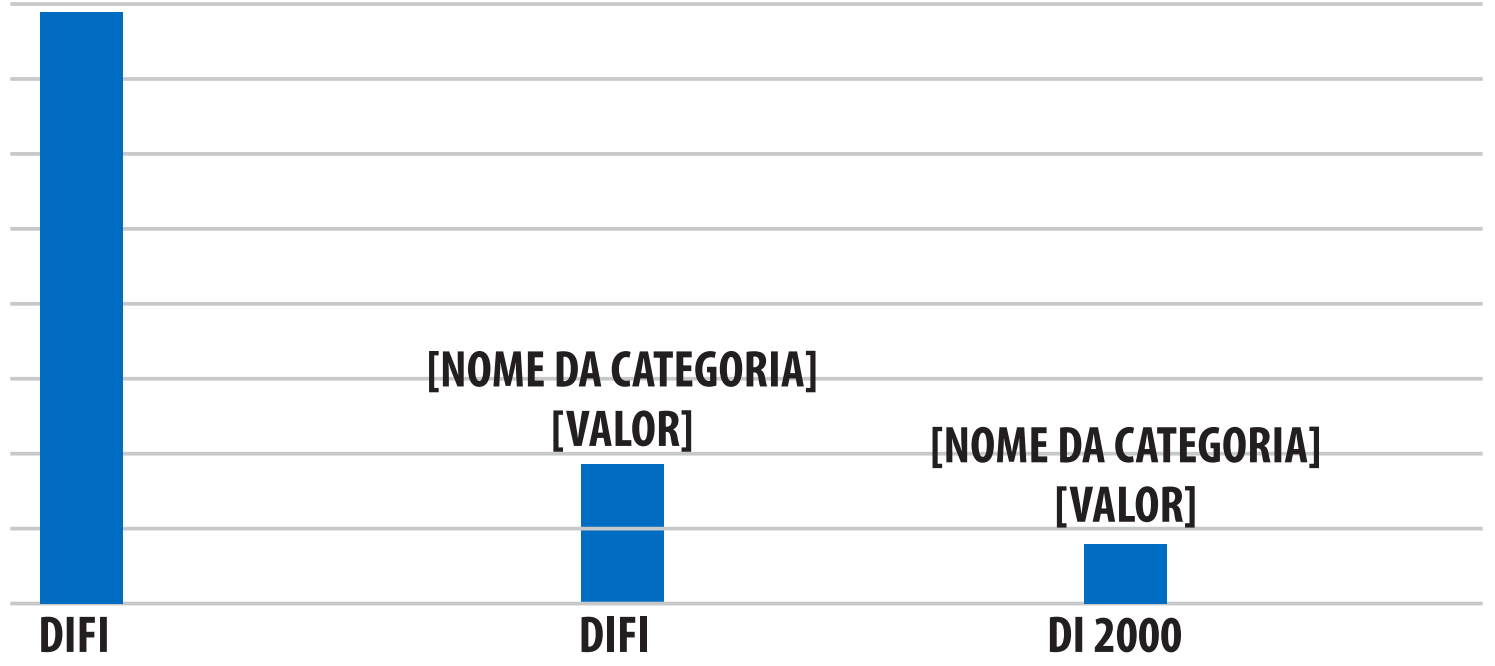

Fonte: Elaboração da autora a partir de dados da PMM - 2013

O DIF I possui 73 indústrias instaladas numa área de 1.013 hectares, a maior área industrial do estado do Ceará. Entre os três distritos é o que apresenta melhor infraestrutura, sistema de abastecimento de água e energia (elétrica e de gás natural), transporte público rodoviário e metrô, rede de esgoto, contendo uma das maiores estações de tratamento de efluentes (ETE) da América do Sul, com 70 ha de área, além de uma moderna rede de comunicação.

As indústrias intaladas nos outros dois distritos somam um total de 27, sendo 19 delas pertencentes ao DIF III e 8 ao DI 2000, distribuídas respectivamente numa área de 164ha e 40,5ha. Estes dados revelam as disparidades espaciais e econômicas existentes entre os distritos industriais mais recentes (DIF III DI 2000) $)^{8}$ e o mais antigo. Convém mencionar que estes dois distritos apresentam certos problemas infraestuturais, principalmente no que se refere ao uso e ocupação do solo e ao sistema público de transporte, que terminam por obstacularizar a implantação de mais indústrias em suas áreas.

O fato dos distritos não estarem operando com todo vapor, não impedem que Maracanaú seja considerado o maior centro industrial do Ceará, sendo seu Produto Interno Bruto (PIB) balizado fundamentalmente no setor industrial, com um percentual de $52,20 \%$, quase o dobro de todo o Estado 23,70\% (tabela 04). O setor de serviço também é um grande gerador de divisas $(47,71 \%)$ e a agropecuária, atividade característica do setor primário, tradicionalmente rural, representa menos de 1\% do PIB.

8 DI F III foi criado no ano de 1998 e o DI 2000 foi criado em 1993. 
Tabela 4 - Produto Interno Bruto por Setor Econômico - 2010

\begin{tabular}{lcc}
\multicolumn{1}{c|}{ DISCRIMINAÇÃO } & MUNICÍPIO & ESTADO \\
\hline PIB a preços de mercado (R\$ mil) & 4.100 .336 & 77.865 .415 \\
\hline PIB per capita (R\$ 1,00) & 19.549 & 9.217 \\
\hline PIB por setor (\%) & & 4,2 \\
\hline Agropecuária & 0,09 & 23,7 \\
\hline Indústria & 52,2 & 72,1 \\
\hline Serviço & 47,71 & \\
\hline
\end{tabular}

Fonte: Instituto Brasileiro de Geografia e Estatística (IBGE)/Instituto de Pesquisa e Estratégia Econômica do Ceará (IPECE).

Ainda com relação ao PIB, Maracanaú detém a maior participação (5,45\%) no Produto Interno Bruto estadual ficando atrás apenas da capital, Fortaleza (IPECE - 2010). Cumpre observar que esta colocação de destaque no ranking da economia cearense é decorrente das atividades industriais desenvolvidas no município.

É inegável a contribuição que teve a implantação do DIF I para a melhoria da infraestrutura de Maracanaú, que era antes desse advento, praticamente inexistente. Segundo dados da Companhia de Água e Esgoto do Ceará - CAGECE, em 2011, a taxa de cobertura urbana foi de $77,52 \%$, ou seja, a maioria da população e acesso a água tratada. No que se refere ao esgotamento sanitário, observa-se na tabela 05 , que a cobertura da rede de esgoto segue o baixo padrão estadual de atendimento deste serviço sanitário, apenas 32,13\% de todo o esgoto produzido no município é coletado.

\section{Tabela 5 - Esgotamento Sanitário 2012}

\begin{tabular}{|c|c|c|c|}
\hline \multirow[b]{2}{*}{ DISCRIMINAÇÃO } & \multicolumn{3}{|c|}{ Esgotamento Sanitário } \\
\hline & Município & Estado & $\begin{array}{l}\text { \% sobre o total } \\
\text { do Estado }\end{array}$ \\
\hline Ligações reais & 1.991 & 493.930 & 0,4 \\
\hline Ligações ativas & 1.897 & 468.501 & 0,4 \\
\hline Taxa de cobertura urbana de esgoto \% (1) & 32,13 & 34,62 & 0 \\
\hline
\end{tabular}

Fonte: Companhia de Água e Esgoto do Ceará (CAGECE). Dados referente à 2011.

Quanto aos resíduos sólidos, 95,95\% dos domicílios de Maracanaú são atendidos pelo serviço de coleta de lixo (CENSO, 2010), e tem sua disposição final no Aterro Metropolitano Sul. De acordo com a Coordenação de Limpeza Pública, a coleta é realizada entre duas a três vezes por semana, dependendo do bairro, com exceção do Centro da cidade, onde é realizada diariamente. 
A legislação brasileira estabelece que é de responsabilidade da prefeitura a gestão do lixo doméstico, cabendo-lhe a missão de garantir sua coleta e disposição final. Por outro lado, no que concerne os resíduos industriais, objeto deste estudo, o transporte e disposição final é de responsabilidade do gerador, o qual fica sujeito aos regulamentos e à fiscalização do poder público.

Vale advertir que, não existe em Maracanaú, apesar de seu significativo polo industrial, um aterro para resíduos classe I, nem incinerador ${ }^{9}$ ou empresa de coprocessamento $^{10}$, locais ambientalmente adequados para disposição final deste tipo de resíduo. Então, grande parte do resíduo industrial gerado é remetido para fora do município, e os resíduos que não são coprocessados ou incinerados dentro do estado, vão para outros estados do nordeste, como Pernambuco e Bahia, haja visto também a inexistência de aterro classe I no Ceará (figura 02).

\section{Figura 3 - Localização dos Aterros para Resíduos Classe I}

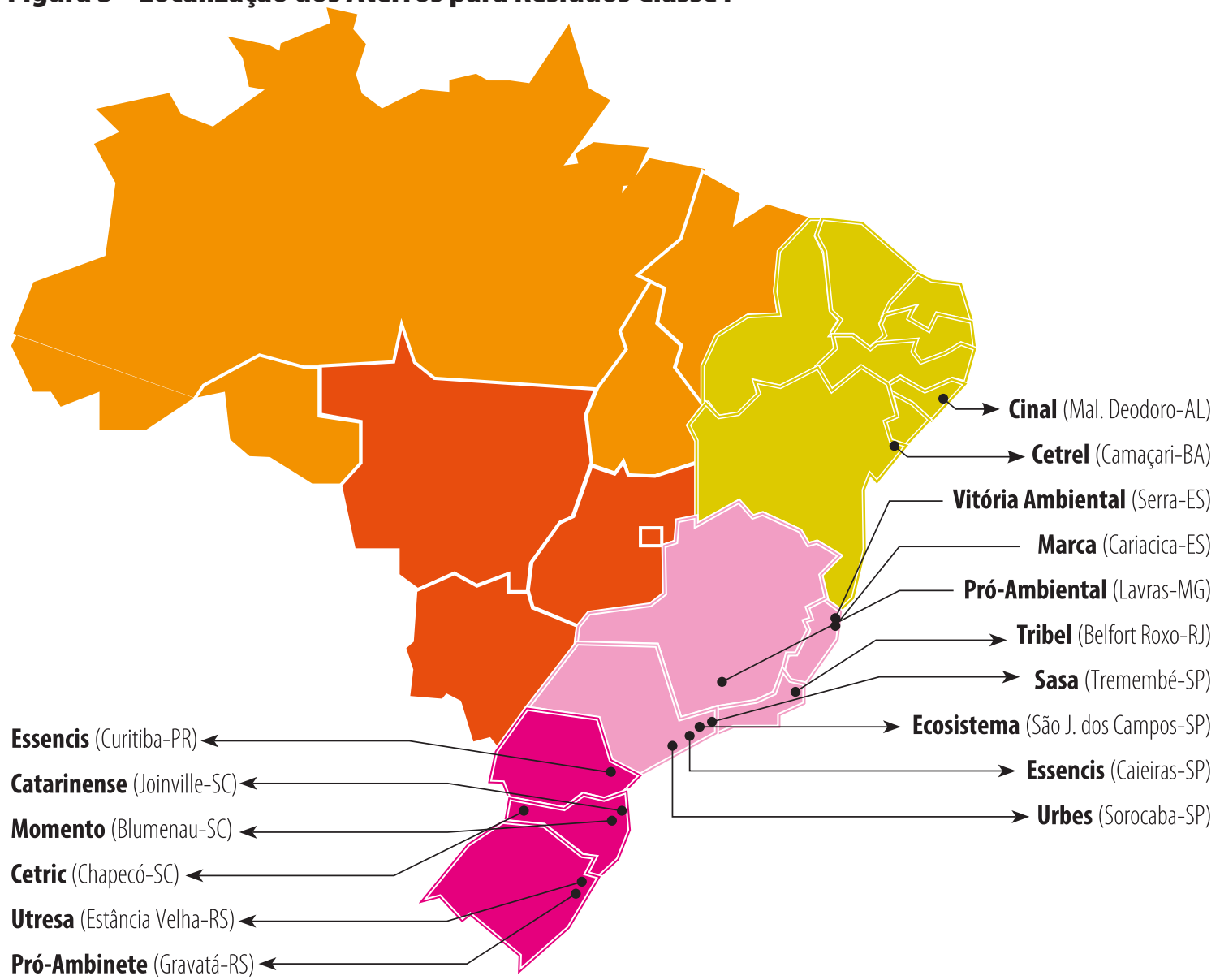

Fonte: ABRELPE (2006)

9 Incinerador - equipamento projetado para o tratamento térmico de resíduos sólidos com temperaturas acima de $800^{\circ} \mathrm{C}$. (IPT, 2000)

${ }_{10}$ Coprocessamento - tecnologia de destruição térmica de resíduos e passivos ambientais em fornos de cimento. 
Observa-se no mapa da figura 02, através da espacialização geográfica das unidades receptoras de resíduos industriais no Brasil, que a quantidade de aterros classe I está muito aquém da necessidade nacional, concentrando-se mais nas regiões sul e sudeste. Para as pequenas e médias empresas localizadas nas regiões norte e centro-oeste, o custo do transporte consiste em um grande obstáculo para o tratamento e disponibilização de seus resíduos.

\section{CONSIDERAÇÕES FINAIS}

A gestão dos resíduos sólidos revela diferenças na qualidade de vida e de acesso aos serviços públicos na cidade, o contraste entre as áreas nobres e periféricas é gritante, traz à tona a produção desigual do espaço urbano. Ainda hoje, na Região Metropolitana de Fortaleza(RMF), da qual Maracanaú faz parte, há bairros que não possuem serviço de coleta de lixo; são ambientes expostos a todos os agentes patogênicos oriundos da disposição inadequada de resíduos, promovendo uma exposição desigual aos riscos.

Vale destacar que a complexidade existente nos estudos de análise de risco é algo notório, pois compreender a natureza e determinar o nível de risco, envolve não apenas elementos pragmáticos, mas também subjetivos que varia de indivíduo para indivíduo. Considera-se a análise de risco dos resíduos industriais classe I, ainda mais complexa, pois não há transparência, por parte dos donos das indústrias, quanto ao manejo dos mesmos. A consequência, é uma população desinformada sobre a realidade dos perigos que se encontra exposta, restando-lhe apenas confiar na fiscalização de órgãos públicos, constituídos na maioria das vezes por equipes reduzidas e desacreditadas.

Neste sentido as primeiras evidências reveladas pela presente pesquisa, indicam que ineficácia de uma fiscalização efetiva e a inexistência de um aterro industrial no estado do Ceará dificultam o gerenciamento adequado deste tipo de resíduos e corrobora com a hipótese de que a gestão dos resíduos sólidos classe I no distrito industrial de Maracanaú-CE expõe os moradores a situações conjunturais de risco ambiental e vulnerabilidade social. A causa pode estar na falta de informação técnica, nas dificuldades de aparelhamento administrativo e, sobretudo, na ausência de pressão por parte de segmentos interessados na manutenção do status quo. Diante do exposto, é inegável a urgência do cumprimento da Política Nacional de Resíduos Sólidos, articulada a políticas estaduais e municipais correspondentes. 


\section{REFERÊNCIAS}

1. ALMEIDA, Lutiane Queiroz de. Riscos ambientais e vulnerabilidade nas cidades brasileiras: conceitos, metodologias e aplicações. São Paulo, SP. Cultura Acadêmica, 2012.

2. ALVES, H. P. F. Vulnerabilidade socioambiental na metrópole paulistana: uma análise

3. sociodemográfica das situações de sobreposição espacial de problemas e riscos sociais e ambientais. Revista Brasileira de Estudos de população, 2006, vol. 23, n. 1, São Paulo.

4. ASSOCIAÇÃO BRASILEIRA DE NORMAS TÉCNICAS NBR 10.004/2004: Classificação de resíduos. www.aslaa.com.br/legislacoes/NBR\%20n\%2010004-2004.pdf>. Acesso em:30.mar. 2013.

5. .NBR 10.004: resíduos sólidos - classificação. Disponível em :www.abntcatalogo. com.br/norma.aspx?ID=936. Acesso em:28.jul.2014.

6. ASSOCIAÇÃO BRASILEIRA DE EMPRESAS DE TRATAMENTO, RECUPERAÇÃO E DISPOSIÇÃO DE RESÍDUOS ESPECIAIS. Panorama dos Resíduos Sólidos no Brasil. Disponível em: www.abrelpe.org.br/Panorama/panorama2013.pdf. Acesso em:28.jul.2014.

7 . Panorama dos Resíduos Sólidos no Brasil. Disponível em: www.abrelpe.org.br/ Panorama/panorama2006.pdf. Acesso em:29.jul.2014.

8. BARCELLOS, Frederico Cavadas e OLIVEIRA, Sônia Maria M. C. de. Novas Fontes de Dados sobre Riscos Ambientais e Vulnerabilidade Social. Disponível em: www.anppas.org.br/ encontro4/cd/.../GT11-848-561-20080509105611.pdf. Acesso em: 28.mai. 2013.

9. BELLA, D. A. 1987. Engineering and Erosion of Trust. Journal of Professional Issues in Engineering. 113: 117-129.

10. CASTRO, Cleber Marques de, PEIXOTO, Maria Naíse de Oliveira et al. Riscos Ambientais e Geografia: Conceituações, Abordagens e Escalas. Anuário do Instituto de Geociências - UFRJ. Vol. 28-2/2005. Disponível em: 2005/Anuario_2005_11_30.pdf. Acesso em: 28.mai. 2013.

11. COMPANHIA DE TECNOLOGIA DE SANEAMENTO AMBIENTAL-CETESB. Norma Tecnica P4 261 Risco de Acidente de Origem Tecnológica - Método para decisão e termos de referência. Disponível em: www.cetesb.sp.gov.br/gerenciamento.../Emeg?...Normas-CETESB-p426.. Acesso em:

12. CONSELHO NACIONAL DO MEIO AMBIENTE - CONAMA 313. Inventário Nacional de Resíduos Sólidos Industriais. Disponível em: www.mma.gov.br/port/conama/legiabre.cfm? codlegi=335. Acesso em: 14.jun. 2013.

13. BECK, Ulrich. Sociedade de risco: rumo a uma outra modernidade. São Paulo: Ed. 34, 2010.

14. CALDERONI, Sabetai. Os Bilhões Perdidos no Lixo. $4^{\text {a }}$ edição. São Paulo: Humanitas Editora/FFLCH/USP, 2003.

15. GIDDENS, A. 1991. As Conseqüências da Modernidade. São Paulo, Edusp.177 p.

16. FARIAS, Airton de. História do Ceará. 5a edição. Fortaleza: Edições Livro Técnico 2009.

17. FERREIRA, Cynthia Fantoni Alves; ZANTA, Viviana Maria. Gerenciamento Integrado de Resíduos Sólidos Urbanos. Disponível em: pt.scribd.com/doc/141638069/LIVRO-PROSAB-RSU. Acesso em: 28.jul. 2014. 
18. INSTITUTO BRASILEIRO DE GEOGRAFIA E ESTATÍSTICA. Censo 2010. Disponível em: www.ibge.gov.br/. Acesso em: 29.jun. 2014.

19. IPECE, Instituto de Pesquisa e Estratégia Econômica do Ceará. Perfil Básico Municipal 2013 Maracanaú. Disponível em: www.ipece.ce.gov.br/. Acesso em: 27.jun. 2014.

20. IPT/CEMPRE. Lixo Municipal: Manual de Gerenciamento Integrado. $2^{\mathrm{a}}$ ed. São Paulo, 2000.

21. JACOBI, Pedro Roberto. Cidade e meio ambiente: percepções e práticas em São Paulo. São Paulo: Annablume, 2000.

22. . e BESEN, Gina Rizpah. Gestão de Resíduos Sólidos na Região Metropolitana de

São Paulo Avanços e Desafios. São Paulo em Perspectiva, v. 20, n. 2, p. 90-104, abr./jun. 2006.

23. Gestão de resíduos sólidos em São Paulo: desafios da sustentabilidade. Estudos avançados, São Paulo, v. 25, n. 71, Abr. 2011. Disponível em:http://www.scielo. br/scielo.php?script=sci_arttext\&pid=S010340142011000100010\&lng=en\&nrm=iso. Acesso em: 28. ago.2014.

24. MARX, Karl. O Capital Crítica da Economia Política. Vol. 1. São Paulo, Editora Nova Cultural Ltda, 1988.

25. MINISTÉRIO do Meio Ambiente \& INSTITUTO Brasileiro de Defesa do Consumidor. POLÍTICA NACIONAL DE RESÍDUOS SÓLIDOS LEI No 12.305, DE 2 DE AGOSTO DE 2010. Disponível em: http://www.planalto.gov.br/ccivil_03/_ato2007-2010/2010/lei/l12305.htm. Acesso em: 02 nov. 2012.

26. MINISTÉRIO do Meio Ambiente e GOVERNO do Estado do Ceará. Atualização da Regionalização para a Gestão Integrada de Resíduos Sólidos no Estado do Ceará. Brasília:Tramitty, 2012.

27. MOURÃO, Ada Raquel Teixeira Mourão; Cavalcante, Sylvia. O processo de construção do lugar e da identidade dos moradores de uma cidade reinventada. Disponível em: www.scielo.br/scielo.php?pid=S1413-294X2006000200003\&script. Acesso em: 30.jun.2014.

28. POLÍTICA FEDERAL DE RESÍDUOS SÓLIDOS LEI No 11.445, DE 05 DE JANEIRO DE 2007. Disponível em: http://www.planalto.gov.br/ccivil_03/_ato2007-2010/2007/lei/l11445. htm. Acesso em: 02.mai.2014.

29. SANTOS, Milton. Metamorfoses do Espaço Habitado, Fundamentos Teóricos e Metodológico da Geografia. São Paulo: Hucitec, 1988.

30. VEYRET, Yvette,(organizadora). Os riscos: o homem como aggressor e vítima do meio ambiente. 1. ed., $1^{\text {a }}$ reimpressão. São Paulo: Contexto, 2007.

31. WALDMAN, Maurício. Lixo: cenários e desafios: abordagens para entender os resíduos sólidos. São Paulo: Cortez, 2010.

32. SLOVIC, P. 1998. Perceived Risk, Trust and Democracy. In: LÖFSTEDT, R. \&FREWER, L. (eds.) Risk \& Modern Society. London, Earthscan Reader. 256 p.

Artigo recebido em 30 de abril de 2015

Artigo aceito em 21 de junho de 2015 